OPEN ACCESS

Edited by:

Sandeep Singh,

Central University of Punjab, India

Reviewed by:

Daniela Patrizia Foti,

Magna Græcia University, Italy

Chen Chen,

The University of Queensland,

Australia

*Correspondence:

Vasudevan Seshadri

seshadriv@nccs.res.in

Specialty section: This article was submitted to Genomic Endocrinology, a section of the journal

Frontiers in Endocrinology

Received: 30 November 2017 Accepted: 04 April 2018

Published: 23 April 2018

Citation:

Vaishya S, Sarwade RD and Seshadri V (2018) MicroRNA,

Proteins, and Metabolites as

Novel Biomarkers for Prediabetes, Diabetes, and Related Complications.

Front. Endocrinol. 9:180. doi: 10.3389/fendo.2018.00180

\section{MicroRNA, Proteins, and Metabolites as Novel Biomarkers for Prediabetes, Diabetes, and Related Complications}

\author{
Suniti Vaishya ${ }^{1}$, Rucha D. Sarwade ${ }^{2}$ and Vasudevan Seshadri ${ }^{1 *}$ \\ ${ }^{1}$ National Centre for Cell Science, Pune, India, ${ }^{2}$ Department of Biotechnology, Savitribai Phule Pune University, Pune, India
}

Type 2 diabetes mellitus (T2DM) is no more a lifestyle disease of developed countries. It has emerged as a major health problem worldwide including developing countries. However, how diabetes could be detected at an early stage (prediabetes) to prevent the progression of disease is still unclear. Currently used biomarkers like glycated hemoglobin and assessment of blood glucose level have their own limitations. These classical markers can be detected when the disease is already established. Prognosis of disease at early stages and prediction of population at a higher risk require identification of specific markers that are sensitive enough to be detected at early stages of disease. Biomarkers which could predict the risk of disease in people will be useful for developing preventive/proactive therapies to those individuals who are at a higher risk of developing the disease. Recent studies suggested that the expression of biomolecules including microRNAs, proteins, and metabolites specifically change during the progression of T2DM and related complications, suggestive of disease pathology. Owing to their omnipresence in body fluids and their association with onset, progression, and pathogenesis of T2DM, these biomolecules can be potential biomarker for prognosis, diagnosis, and management of disease. In this article, we summarize biomolecules that could be potential biomarkers and their signature changes associated with T2DM and related complications during disease pathogenesis.

Keywords: microRNA, proteins, metabolites, type 2 diabetes mellitus, biomarker

\section{INTRODUCTION}

Type 2 diabetes mellitus (T2DM) is a metabolic disorder which is the cause of serious concern worldwide. According to the International Diabetes Federation report, global burden of diabetes affected population will be increased to $\sim 592$ million by the year 2035 (1). Developing countries like India will have $\sim 109$ million of affected people, making diabetes no more a developed world disease. Characterized by hyperglycemia, T2DM is a group of metabolic disorders resulting from defects in insulin secretion, action or both (2). After the onset of disease, T2DM further leads to macrovascular, microvascular, and neurological complications. The clinical manifestation of a complex metabolic disease like T2DM is delayed by years, thereby restricting its timely diagnosis. It has been demonstrated that there is a significant relative risk reduction of cardiovascular Diseases (CVDs) and all-cause mortality in individuals undergoing regular medical examination emphasizing the importance of early diagnosis of the disease (3). Thus, the identification of highrisk individuals even before the prediabetes stage, when the beta cells are relatively intact, is of paramount importance for effective intervention, preventing progression to overt disease. 
Despite several advances in understanding of disease establishment, progression, and related pharmacotherapy, there has been a sustained increase in diabetes-affected population. The availability of effective interventions for prevention and delaying the onset of T2DM has created urgency for the early identification of individuals at risk. Besides, as larger proportion of affected population now comes from developing countries, cost-effectiveness and affordability of diagnostic tests are also an issue. The practical difficulty in procuring samples to test blood glucose and serum insulin levels, the intra-individual variability in blood glucose levels (4), the high-risk familial genes adding no value in predicting the onset of the disease (5), and the fact that only $20 \%$ of the obese individuals are actually at a risk of developing full-blown T2DM (6) limits the use of existing biomarkers.

A biomarker is a biomolecule/biological state that could be used for the prognosis, diagnosis, and follow-up of the pathological state of a disease. These could also be used to assess the severity of disease. There are different kinds of biomarkers [including biomolecules like proteins, microRNAs (miRNA), etc.] that are being used for the diagnosis of many diseases like T2DM, cancer, neurological diseases, etc. $(7,8)$. Pathophysiology of T2DM is substantially contributed by adipocyte signaling (9), inflammation (10), endothelial dysfunction (11), iron overload (12), incretin abnormalities (13), and inconsistencies in circadian systems $(14,15)$. Biomarkers that are designed taking into account these parameters would help improve screening approaches for T2DM.

\section{CURRENT UNDERSTANDING OF DIAGNOSTIC MARKERS FOR T2DM}

The current diagnostic thresholds for T2DM according to Expert Committee on the Diagnosis and Classification of Diabetes are fasting plasma glucose (FPG) of $\geq 126 \mathrm{mg} / \mathrm{dl}(7.0 \mathrm{mmol} / \mathrm{l})$ and 2-h post-prandial plasma glucose of $\geq 200 \mathrm{mg} / \mathrm{dl}(11.1 \mathrm{mmol} / \mathrm{l})$ and $\mathrm{HbAlc}$ of $\geq 6.5 \%(47.5 \mathrm{mmol} / \mathrm{mol})$. These criteria are largely based on an association of cross-sectional glycemic and HbA1c levels, respectively, with diabetic retinopathy $(2,16)$. Prediabetes is an intermediate group of individuals whose plasma glucose levels range between normoglycemia and diabetes. The fasting glucose concentration of $110-125 \mathrm{mg} / \mathrm{dl}$ (6.1-6.9 mmol/l) by World Health Organization (WHO) and $100-125 \mathrm{mg} / \mathrm{dl}(5.6-6.9 \mathrm{mmol} / \mathrm{l})$ by American diabetes association (ADA) [also termed impaired fasting glucose (IFG)], and $\mathrm{ADA}$ and WHO recommended 2-h glucose concentration cutoffs of $140-199 \mathrm{mg} / \mathrm{dl}(7.8-11.0 \mathrm{mmol} / \mathrm{l})$ [also termed impaired glucose tolerance (IGT)] specifically define the condition of prediabetes and their long-term outcomes (16). People with IFG, IGT ( $2 \mathrm{~h}$ after meal), or abnormal HbA1c values have a higher risk of developing T2DM and associated pathophysiology. Several clinical characteristics have been associated with T2DM (17). Apart from blood glucose level and HbA1c, other parameters like levels of blood cholesterol, lipoproteins, C-peptide, blood pressure, etc. are also taken into account to predict T2DM (18). However, except for blood glucose assessment and $\mathrm{HbA1c}$, all other parameters are not specific to T2DM (18).
Moreover, hyperglycemia assessed by fasting glucose and 2-h blood glucose estimation only gives an idea of the glucose level at a single time point. Hence, testing them more than once is required. Also, the complexity of clinical condition cannot be fully described by blood glucose level. HbA1c is a more reliable measurement than fasting glucose level as it indicates the average levels of plasma glucose over several weeks and is better correlated with chronic complications. HbA1c assessment does not require fasting and has a greater pre-analytical stability than plasma glucose. Hyperglycemia is the main biochemical phenomenon associated with diabetes which further leads to elevation in glycated proteins (HbA1c). However, there is a time gap between hyperglycemia and rise in glycated hemoglobin level, resulting in delayed diagnosis of the onset of diabetes using $\mathrm{HbA} 1 \mathrm{c}$ levels. Standardization of $\mathrm{HbA} 1 \mathrm{c}$ assay is required, whereas glucose assay is standardized and easier to implement. Moreover, most of these classical biomarkers are useful only after the establishment of disease and fails to predict disease at a prediabetic condition. Besides, classical markers are inconclusive to predict the pathogenesis of T2DM which eventually leads to severe complications including chronic heart disease, diabetic nephropathy (DN), retinopathy, etc. Thus, novel, more specific, noninvasive, stage-related biomarkers that are accurate in the diagnosis of initiation and progression of T2DM are needed.

\section{EMERGING ROLE OF miRNAs AS BIOMARKERS IN TYPE 2 DIABETES AND RELATED COMPLICATIONS}

MicroRNAs are small, 20-25 nt long noncoding RNA molecules which normally binds to the $3^{\prime}$ end of its target mRNAs to inhibit its translation, eventually leading to a reduced gene expression (19). miRNAs can target multiple genes and are involved in the regulation of multiple functions in cells. It has been estimated that miRNA target site is conserved in the $3^{\prime}$ UTR of more than $60 \%$ of all mammalian mRNAs; thus, miRNAs are likely to be important regulators in the cell (20). Owing to their stability and presence in various body fluids, miRNAs emerged as potential biomarkers for T2DM and related complications. Besides, the differential expression of miRNAs in various tissues has been reported in T2DM and related complications (Table 1). It has been suggested that miR-103 and miR-143 may regulate the subcutaneous adipose tissue and the development of T2DM in mice. miR-103 may also be involved in the regulation of adipose and the control of glucose metabolism in humans (21). Plateletderived miR-103 was found to negatively regulate the expression of secreted frizzled-related protein 4 , which is a potential risk biomarker for the onset of diabetes mellitus (prediabetes). miR103 was downregulated in individuals with prediabetes (22). The expression of various miRNAs is altered in patients with diabetes-related complications including microvascular complications (23). It has been suggested that the expression of miRNAs in different tissues and body fluids also reflects disease pathology. For instance, the expression of five miRNAs miR-661, miR-571, miR-770-5p, miR-892b, and miR-1303 were increased in T2DM 
TABLE 1 | MicroRNAs (miRNAs) associated with type 2 diabetes mellitus (T2DM) and associated complications.

\begin{tabular}{|c|c|c|c|c|c|}
\hline S. No. & & miRNA & Target & Expression level & Reference \\
\hline 1. & \multirow[t]{24}{*}{ Obesity and T2DM } & $\operatorname{miR}-124 a$ & Mtpn, Foxa2, Flot2, Akt3, Sirt1, and NeuroD1 & Up & $(22)$ \\
\hline 2. & & miR-101 & & Up & $(44)$ \\
\hline 3. & & miR-802 & & Up & $(44)$ \\
\hline 4. & & miR-96 & Noc2 & Down & (35) \\
\hline 5. & & $\operatorname{miR}-103$ & SFRP4 & Up & (45) \\
\hline 6. & & miR-375 & Mtpn, PDK1 & Up/down & $(44)$ \\
\hline 7. & & miR-23a & SMAD4 & Up & $(21)$ \\
\hline 8. & & miR-132 & NF-kappa B & Down & $(46)$ \\
\hline 9. & & miR-34a & SIRT1 & Down & (46) \\
\hline 10. & & $\operatorname{miR}-145$ & ADAM17 & Down & $(21)$ \\
\hline 11. & & miR-221 & CAV-1 & Up & $(46)$ \\
\hline 12. & & $\operatorname{miR}-144$ & IRS-1 & Up & $(21)$ \\
\hline 13. & & $\operatorname{miR}-146 a$ & TRAF6 & Up & (21) \\
\hline 14. & & miR-29 & Spry1, AKT3 & Up & $(21)$ \\
\hline 15. & & miR-34a & FGFR1, BetaKL & Up & $(21)$ \\
\hline 16. & & miR-15a & UP2 & Down & (34) \\
\hline 17. & & miR-126 & IRS-1 & Down & $(34,46)$ \\
\hline 18. & & miR-29b & DNMT1 & Down & (34) \\
\hline 19. & & miR-223 & Glut4, HDAC4, Pknox1, Nfat5 & Down & (34) \\
\hline 20. & & miR-335 & Mest & Up & $(47)$ \\
\hline 21. & & miR-107 & CAV-1 & Up & $(47)$ \\
\hline 22. & & miR-223 & STAT3 & Up & $(46)$ \\
\hline 23. & & $\mathrm{miR}-143$ & ORP8, AKT & Up & $(48)$ \\
\hline 24. & & miR-935 & CNR1, ESR1 & Up & $(46)$ \\
\hline 25. & \multirow[t]{5}{*}{ Diabetic retinopathy } & $\mathrm{miR}-146 \mathrm{a}$ & Fibronectin & Down & $(49)$ \\
\hline 26. & & miR-200b & VEGF & Down & $(50)$ \\
\hline 27. & & miR-29b & $\operatorname{RAX}$ & Up & $(40)$ \\
\hline 28. & & miR-195 & SIRT1 & Up & (51) \\
\hline 29. & & $\operatorname{miR}-486$ & p53 & Up & (52) \\
\hline 30. & \multirow[t]{16}{*}{ Diabetic nephropathy } & miR-192 & SIP1, ZEB1/ZEB2 & Up & $(53-55)$ \\
\hline 31. & & $\operatorname{miR}-21$ & PTEN, PI3K, Akt & Up & $(56,57)$ \\
\hline 32. & & miR-377 & PAK/SOD & Up & (58) \\
\hline 33. & & miR-216a & PTEN, Ybx1 & Up & $(59,60)$ \\
\hline 34. & & miR-217 & PTEN & Up & (60) \\
\hline 35. & & miR-93 & VEGF & Up & $(61)$ \\
\hline 36. & & $\mathrm{miR}-146 a$ & & Up & (62) \\
\hline 37. & & $\operatorname{miR}-155$ & & Up & (63) \\
\hline 38. & & miR-25 & NOX-4 & Down & (64) \\
\hline 39. & & miR-215 & ZEB2 & Down & $(55)$ \\
\hline 40. & & miR-29a/b/c & Col1, Col4 & Down & (65) \\
\hline 41. & & $\operatorname{miR}-135$ & TRPC1 & Up & (66) \\
\hline 42. & & miR-150-5p & & Up & $(41)$ \\
\hline 43. & & miR-362-3p & & Up & $(41)$ \\
\hline 44. & & miR-877-3p & & Up & $(41)$ \\
\hline 45. & & $\operatorname{miR}-15-5 p$ & & Down & $(41)$ \\
\hline 46. & \multirow[t]{10}{*}{ Diabetic cardiovascular disease } & $\mathrm{miR}-16$ & Cox-2 & Down & (67) \\
\hline 47. & & miR-133 & RhoA, Cdc42 & Down & (68) \\
\hline 48. & & miR-223 & GLUT4 & Up & (69) \\
\hline 49. & & miR-492 & Resistin & Down & (70) \\
\hline 50. & & miR-320 & IGF-1 & Up & (24) \\
\hline 51. & & $\mathrm{miR}-503$ & Ccne1, Cdc25A & Up & (25) \\
\hline 52. & & miR-373 & Mef2C & Down & (71) \\
\hline 53. & & miR-1 & Pim-1 & Up & $(72)$ \\
\hline 54. & & miR-504 & Grb10, Egr2 & Up & (73) \\
\hline 55. & & miR-24 & & Down & $(74)$ \\
\hline 56. & \multirow[t]{5}{*}{ Diabetic neuropathy } & miR-184-5p & & & (75) \\
\hline 57. & & miR-190a-5p & & & $(75)$ \\
\hline 58. & & miR-182 & NOX-4 & Up & (23) \\
\hline 59. & & $\mathrm{miR}-146 a$ & & Up & (76) \\
\hline 60. & & miR-29b & Smad3 & Down & (77) \\
\hline
\end{tabular}


(23). miR-126, miR-320, and miR-503 have also been shown to be involved in diabetic cardiovascular disease and endothelial function (24-27). miR-320 expression was also elevated in diabetic rat models (26). Increased levels of miR-18a and decreased levels of miR-34c in peripheral blood mononuclear cells are important markers of chronic stress response and may play a role in T2DM-risk assessment (28). miR-375, an miRNA expressed in pancreas reduces the level of PDK1 kinase, leading to a decreased glucose-stimulated insulin gene expression. The role of miR-375 seems to be conserved across species including humans and mice. miR-375 plays a role in the process of re-differentiating mature human beta cells in vitro and hence can be useful for cell replacement therapy in diabetes. An increased expression of miR-375 in expanded islet cells dampens the PDK1-AKT pathway, as well as GSK3-signaling pathways leading to the regeneration of insulin-producing beta cells (29). Besides, the overexpression of miR-375 suppresses glucose-stimulated insulin secretion by downregulating the expression of myotrophin $(30,31)$. Defective insulin secretion is observed in many T2DM instances, and miR126 seems to play an important role in this process and exhibits a negative relationship with T1DM and T2DM $(32,33)$. In relation to T2DM, a unique circulatory miRNA signature has been identified (34). The levels of four miRNAs miR-126, miR-15a, miR-29b, and miR-223 decrease while miR-28-3p level increases in case of T2DM. These miRNAs are significantly modulated even before the manifestation of the disease, making these small molecules valuable as a prognostic marker for the prediction of T2DM (34). Imbalance in the exocytotic machinery components leads to impaired insulin secretion by the pancreatic $\beta$-cells, resulting in T2DM. Studies have shown the significance of miRNA in the regulation of glucose-stimulated insulin translation, secretion, and exocytosis by pancreatic cells (35-37). Increased levels of miR-335 lead to impaired insulin secretion (38). miR-196a was shown to be regulating the insulin biosynthesis, and its role was suggested to be important during early embryonic development (36). Interestingly, it was shown that the restoration of specific miRNAs can attenuate the progression of disease in animal models. For instance, the rescue of a reduced level of miR-181b in epithelial cells of adipose tissue in a mouse model of obesity leads to an improvement in glucose homeostasis and insulin sensitivity (39). Silent mating type information regulation 2 homolog 1 (Sirt1) is involved in neuroprotection and wound healing. Sirt1 regulates the expression of miR-182 which further overcomes the detrimental effects of hyperglycemia by decreasing the expression of NOX4, leading to corneal nerve regeneration (40). Progression of diabetes leads to complications like diabetic kidney disease (DKD). In comparison to diabetic individuals, patients with DKD were found to be differentially expressing (>2-fold) 496 urinary exosome-derived miRNA species. Four of these were further validated, and it was reported that miR-362-3p, miR-877-3p, and miR-150-5p were upregulated, while miR-15a-5p was downregulated. These miRNAs might be involved in the regulation of DKD through p53, mTOR, and AMPK pathways (41). Similarly, various miRNAs were found to be involved in endothelial function and diabetic cardiovascular diseases (CVD) $(42,43)$. For instance, miR-126 exhibits a lower expression in coronary artery disease and myocardial infarction patients compared with healthy controls. It was suggested that miR-126 regulates endothelial cells by targeting sprout-related protein via Ras/ERK/VEGF and PI3K/Akt/eNOS pathways (43).

\section{PROTEINS AS SPECIFIC MARKER FOR T2DM}

Proteomic analysis of serum, plasma, and other body fluids using 2D-liquid chromatography and mass spectrometric analysis identified many proteins as biomarkers for T2DM and related complications (Figure 1). Fat accumulation in human body before the onset of T2DM promotes the release of adipokines from adipocytes including adiponectin, leptin, glycoalbumin, and retinol-binding protein 4 (RBP4). Among these, adiponectin and leptin are relatively common and are occasionally used as biomarker for diabetes screening. Glycated albumin is also expressed as some percentage of serum albumin and is involved in only short-term glycemic control (78). RBP4 is another adipocyte-derived factor, reported to be involved in the onset of adiposity and insulin resistance. It is mainly produced in the liver and acts on muscle and/or liver via mechanisms that are either retinol-dependent or independent (79). Yang et al. (2005) (80) have shown that the expression of serum RBP4 was higher in insulin-resistant mice and humans with obesity and T2DM. The overexpression of RBP4 in wild-type mice causes insulin resistance while genetic depletion of $R b p 4$ improves insulin sensitivity, suggesting that the depleting level of RBP4 could be helpful in the treatment of T2DM, and levels of RBP4 could serve as a biomarker for T2DM. Proteomic study to assess the association of plasma proteins with the risk of developing T2DM has shown that RBP4 is independently associated with the risk of developing T2DM (81). Similarly, low level of adiponectin was found to be associated with an increased risk of development and progression of T2D in different populations. Candidates with increasing adiponectin had a reduced risk of developing T2D $(p<0.001)(82,83)$. Further, the proteomic analysis of vitreous in diabetic retinopathy has identified six proteins, including pigment epithelium-derived factor, ApoA$1 / 4$, thyroid hormone receptor interactor II, RBP4, and vitamin $\mathrm{D}$ binding, as specific marker for diabetic while control had only Apo-H (84). Festa et al. 2002 (85) have shown the significant relation of C-reactive protein (CRP), fibrinogen, and PAI-1 to the development of T2DM. Serum protein profiles of normal and streptozotocin-induced diabetic rat have identified eight proteins with an increased expression in diabetes (86). One such protein, CRP, was found to be associated with inflammation, the progression of disease, and an increased cardiovascular risk in patients (87). Also, in comparison to healthy individuals, individuals with insulin resistance and T2DM have shown difference in the level of many proteins including interleukin-6, resistin, leptin, adiponectin, and visfatin (88-92). A panel of 64 circulating candidate biomarkers was analyzed to develop a model for the assessment of a 5-year risk of developing T2DM and identified six biomarkers including adiponectin, CRP, ferritin, interleukin-2 receptor $\mathrm{A}$, and insulin that provide a better estimation of the risk of developing T2DM than that of FPG levels 


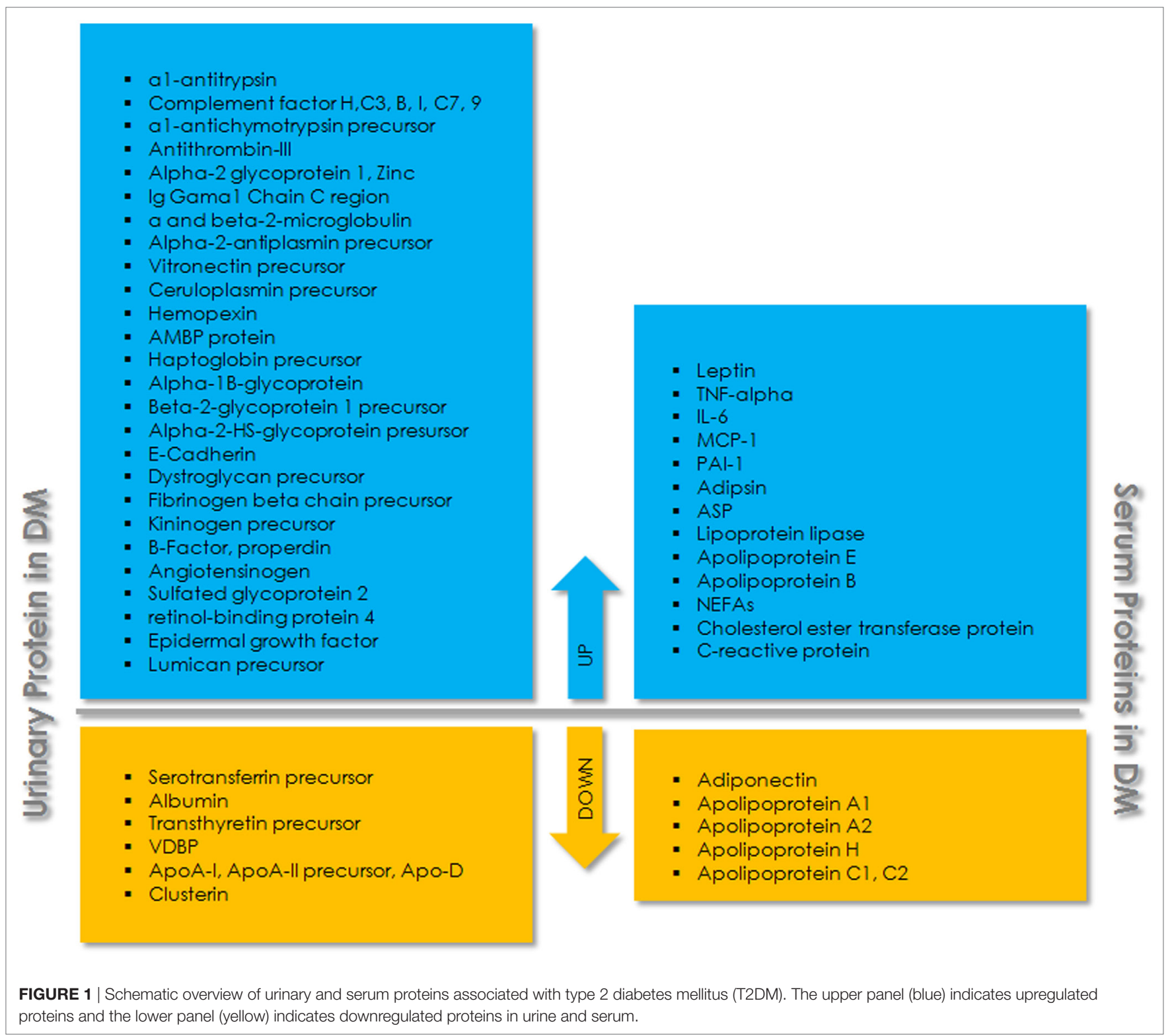

alone (93). Earliest marker for DN includes excreted albumin in urine. However, further studies revealed that albuminuria is not a suitable marker to assess DN. It has been found that most of the diabetic individuals with the progression of renal disease are normoalbuminuric. Also, albuminuric patients with T2DM have shown biopsies with normal glomerular structure or non-DKDs $(94,95)$. This suggests the assessment of DN with albuminuria as biomarker lack specificity and sensitivity. Therefore, more urinary biomarkers were investigated for T2DM complications. Urinary monocyte chemoattractant protein-1 (uMCP-1) and vitamin D-binding protein were found to be significantly elevated in microalbuminuric/macroalbuminuric diabetic patients (96). uMCP-1 and UVDBP levels for the early diagnosis and detection of DN exhibited high sensitivity and specificity. Both of these urinary proteins could be used as potential biomarker for the early detection of DN in T2DM patients. Similarly, E-cadherin levels were found to be elevated $\sim 1.3$-fold in T2DM, which further increases to $\sim 5-8$-fold with progression to DN (97).

In the initial phase of glucose stimulation, insulin biosynthesis is regulated mainly at the translation level. Previously, it was shown that PDI (protein disulfide isomerase) increases insulin translation by binding to its $5^{\prime}$ UTR in response to glucose (98). Several reports suggest that the levels of PDI increase in response to pathological and physiological conditions causing cellular stress (99). The beta cell stress may lead to an increase in the expression of PDI, resulting in high levels of insulin without circulating glucose. Hence, the amount of PDI or beta cell stress markers may serve as potential biomarker in prediabetes.

Recently, it was also shown that chronic hyperinsulinemia in the absence of sufficient glucose progresses to insulin resistance 
faster than their corresponding controls of chronic hyperinsulinemia in the presence of sufficient glucose (100). These studies suggest that cellular stress leading to the production of insulin in the absence of glucose stimulation could be a trigger for insulin resistance. Thus, the uptake of glucose at a regular interval or a reduced cellular stress could be one of the therapeutic interventions to arrest the progress of prediabetic to diabetic situation.

\section{METABOLITES AS BIOMARKERS}

Recent advancement in mass spectrometry has made it possible to profile an organism's metabolic status (101-104). Metabolites are low-molecular-weight compounds that are intermediates or end products of a metabolic pathway. Altered metabolite levels in prediabetic individuals compared to healthy ones may serve as diagnostic biomarkers and enable preventive action (105-110). A large number of metabolites originating from three major fuel sources (carbohydrates, lipids, and proteins) have been implicated as risk factors for the development of T2DM and hence can serve as potential and reliable biomarkers (Figure 2). Serum level of the amino acid glycine is decreased in insulin-resistant individuals. One of the reasons for this could be the increased expression of 5-aminolevulinate synthase 1 (ALAS-H) $(111,112)$. ALAS-H catalyzes the condensation of glycine and succinyl-CoA into 5-aminolevulinic acid. Glycine is also a substrate for gluconeogenesis, and its reduction indicates increased hepatic gluconeogenesis. Insulin resistance entails a greater insulin secretion as a compensatory mechanism before it becomes eventually exhausted due to $\beta$ cell dysfunction (113). Phenylalanine is positively correlated to insulin secretion and it may be involved in the early compensatory stage of insulin secretion (114). The most frequent increase in the levels of branched-chain amino acid (BCAA) like valine, leucine (115), isoleucine, and their derivatives 3-methyl-2-oxovalerate and 3-methyl-2-oxobutyrate (116), is attributed to their reduced catabolism. Reduced activities of the key catabolic enzymes, mitochondrial branched-chain amino acid aminotransferase (BCATm) and branched-chain a-ketoacid dehydrogenase (BCKD) in liver and adipose tissue, lead to the accumulation of these amino acids in insulin-resistant individuals (117). Also, poor biotin metabolism is indicative of insulin resistance, leading to impaired BCAA catabolism (118). Gamma-glutamyl derivatives of valine and isoleucine are formed in glutathionedependent transport of these amino acids. An increase in the circulating concentration of these derivatives may indicate impaired transport of these amino acids in diabetic groups (119). High plasma concentration of $\alpha$-hydroxybutryrate $(2-\mathrm{HB})$ has been consistently shown to be positively correlated with insulin resistance $(115,116)$. It has been postulated that this increase in $2-\mathrm{HB}$ results from alteration in methionine/cystathionine catabolic pathways that produces $2-\mathrm{KB}$ ( $\alpha$-ketobutyrate) and cysteine through cystathionine gamma-ligase activity. An increased availability of precursor 2-KB leads to its higher conversion to 2-HB via lactate dehydrogenase in insulin-resistant state. $\beta$-hydroxybutyrate (or 3-hydroxybutyrate, BHBA) is significantly elevated in diabetes group due to the depletion of hepatic glycogen pool in diabetes, leading to ketogenesis (115,
119). Higher levels of 3 indole-sulfate, creatinine, and homocysteine in diabetic groups may indicate the early onset of impaired renal function that may eventually lead to DN (119). Glomerular filtration rate is a strong determinant of plasma levels of homocysteine and cysteine. Lower plasma levels of cysteine in diabetic patients are indicative of hyperfiltration $(119,120)$. The type of linkage in the phospholipid core and fatty acid residue plays a key role in determining the T2D risk. Lipids with shorter-chain lengths like pelargonate and heptanoate are depleted in IFG conditions when compared to controls and are associated with T2DM while the long unsaturated fatty acids like adrenate and arachidonate are elevated significantly in T2D patients and may help restore insulin sensitivity. Insulin triggers the expression of various fatty acid desaturase. The above observed changes in the lipid profile may be due to a diminished desaturase activity in insulin-resistant individuals. Also, Rhee et al. (2011) have shown that longer chain triacylglycerol (TAGs) are associated with a decreased risk of diabetes, whereas the short chain TAGs are associated with an increased risk, their levels positively correlate with insulin resistance (121). This may suggest impaired triglyceride lipolysis due to dysregulated glucose metabolism. A higher transcriptional level of carnitine-O-acetyl transferase due to the activation of PPAR-alpha pathway in peroxisome (122) produces acetylcarnitine from carnitine and acetyl-CoA in the mitochondrial matrix. This eventually results in elevated levels of acetylcarnitine C2 in IGT individuals (Figure 2).

Accumulating evidences indicate a positive correlation between serum glucose in T2DM and IGT groups compared to normal glucose tolerance (NGT) controls (115, 123). Insulin resistance and insufficient secretion lead to weakened glycolysis and muscle glycogen synthesis, resulting in the obvious accumulation of circulating glucose in the blood. Lactate is elevated in obese, insulin-resistant subjects and can serve as an independent risk factor for the development of T2DM (124-126). A community-based study on obesity and T2DM showed that a decreased oxidative capacity in these individuals leads to higher plasma levels of lactate (127). The serum and urinary levels of fructose are significantly increased in patients with diabetes due to impaired fructose metabolism in hyperglycemia $(115,128,129)$. Elevated levels of modified forms of glucose like desoxyhexose (primarily deoxyglucose), uronic acid (primarily glucuronic acid), dihexose (primarily maltose) (119), and mannose $(116,119)$ in diabetes group reflect an increased availability of glucose, resulting in their biosynthesis. Reduced levels of 1,5 anhydroglucitol (1,5 AG), a deoxy form of glucose, serve as short-term glycemia marker. A decrease in plasma concentrations of 1,5 AG levels in diabetes as compared to the control results from its renal loss stimulated in hyperglycemic conditions by glycosuria (119).

\section{CONCLUDING REMARK AND FUTURE PERSPECTIVES}

MicroRNA-based prognosis, diagnosis, and disease management propose an exciting idea in the context of T2DM. The expression level of miRNAs not only offers an assessment of pathological 


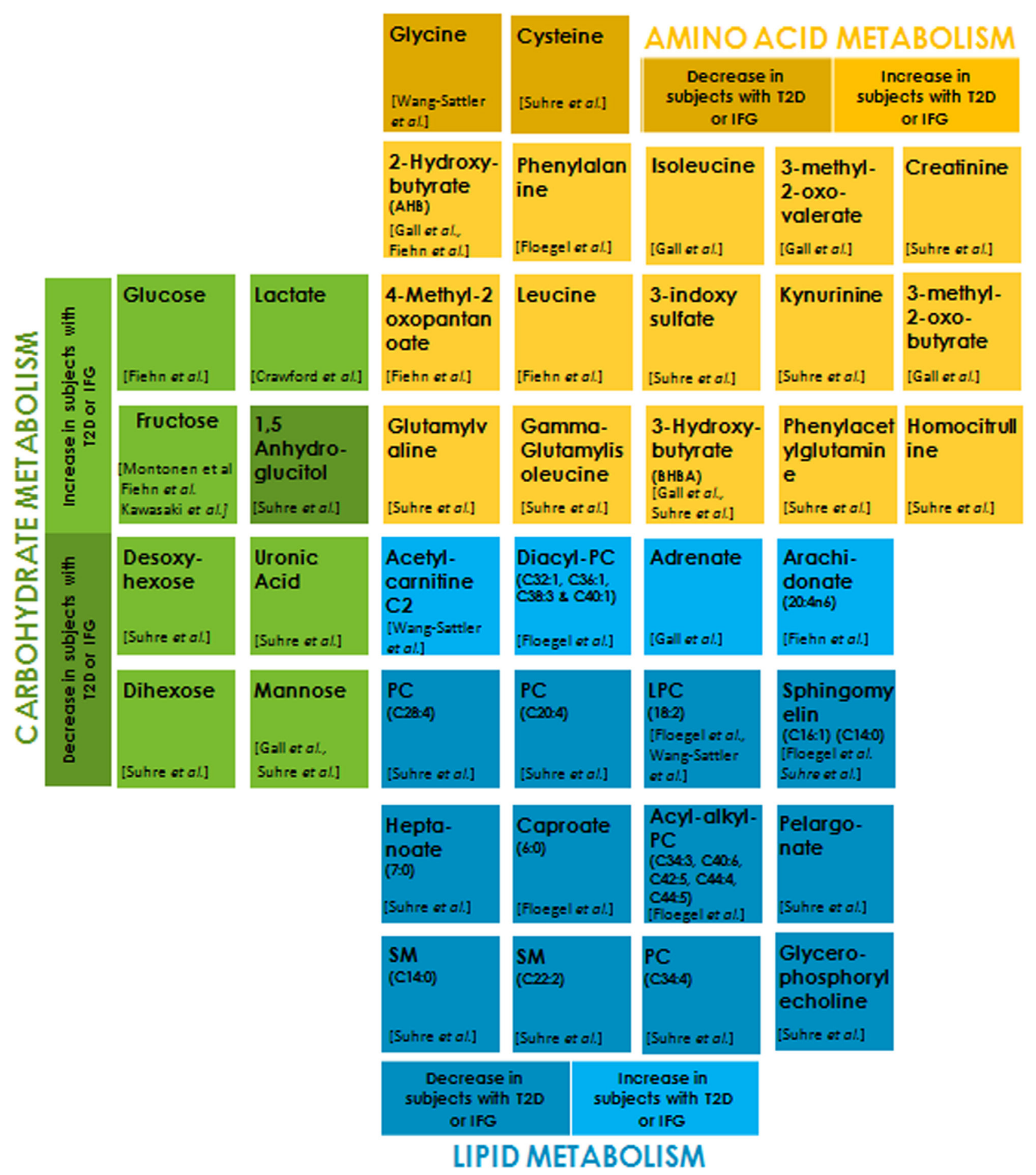

FIGURE 2 | Metabolites belonging to each of the sub groups, i.e., carbohydrate metabolism, amino acid metabolism, and lipid metabolism are differentially color-coded. The light and dark shades of the same color indicate metabolites that are significantly increased and decreased, respectively, in subjects with type 2 diabetes (T2D) or impaired fasting glucose (IFG) with respect to normoglycemic control subjects $(p<0.01-0.0001)$.

state of disease but in some cases could also be used as a therapeutics target. For instance, silencing of miR-103 and miR-107 significantly reduces hyperglycemia in murine model of obesity and T2DM by promoting insulin signaling in liver and adipose tissue (130). Even if the level of many miRNAs promisingly offers an idea about the pathophysiology of T2DM, many issues are yet 
to be solved before using them in therapeutics or as predictive biomarkers. The development of processing procedure of the small biomolecules from body fluids, their storage conditions, and defined sample preparation is still a major issue that needs to be resolved. Most of these identified biomarkers have varying protocols for plasma preparation. Besides, these procedures can alter their level in the final sample. Thus, an optimized protocol for sample preparation needs to be developed for these biomarkers. The physiological issue associated with biomarkers like miRNAs is their implication in regulating multiple molecular pathways. Effect on multiple pathways is needed to be addressed to assess their specificity and accuracy as well as identifying the interconnectivity of various networks.

Most methods for the screening and prevention of T2DM rely on prediabetes individuals already showing a steady decrease of insulin sensitivity. However, these methods may not be as effective as those developed to counter the disease even before the onset of this stage. Hence, it is important to develop biomarker trajectory models that can complement accurately with the existing individual risk assessment methods. For example, the diagnostic potential of $1-\mathrm{h}$ plasma glucose (1-h PG) of $\geq 155 \mathrm{mg} / \mathrm{dl}$ is better than the current threshold levels of FPG, 2-h PG, or HbAcl for prediabetes, identifying high-risk individuals at the so-called pre-prediabetes stage (131). This is because the beta cell function is substantially intact at this stage, and hence lifestyle interventions might be more effective in potentially reducing progression to diabetes (132).

The major shortcoming of multimarker approach is the fact that the overlap of biomarker concentrations between individuals with and without the incidence of T2DM is significant, compromising its discriminative ability. Most novel circulating and/or genetic biomarkers show a high degree of correlation with the existing risk factors adding little or no value. Risk models containing measures of biomarkers belonging to the same casual

\section{REFERENCES}

1. Guariguata L, Whiting DR, Hambleton I, Beagley J, Linnenkamp U, Shaw JE. Global estimates of diabetes prevalence for 2013 and projections for 2035. Diabetes Res Clin Pract (2014) 103(2):137-49. doi:10.1016/j.diabres. 2013.11.002

2. American Diabetes Association. Diagnosis and classification of diabetes mellitus. Diabetes Care (2014) 37(Suppl1):81-90. doi:10.2337/dc14-S081

3. Herman WH, Ye W, Griffin SJ, Simmons RK, Davies MJ, Khunti K, et al. Early detection and treatment of type 2 diabetes reduce cardiovascular morbidity and mortality: a simulation of the results of the Anglo-DanishDutch study of intensive treatment in people with screen-detected diabetes in primary care (ADDITION-Europe). Diabetes Care (2015) 38(8):1449-55. doi: $10.2337 / \mathrm{dc} 14-2459$

4. Mooy JM, Grootenhuis PA, De Vries H, Kostense PJ, Popp-Snijders C, Bouter LM, et al. Intra-individual variation of glucose, specific insulin and proinsulin concentrations measured by two oral glucose tolerance tests in a general Caucasian population: the Hoorn Study. Diabetologia (1996) 39(3):298-305. doi:10.1007/BF00418345

5. Meigs JB, Shrader P, Sullivan LM, McAteer JB, Fox CS, Dupuis J, et al. Genotype score in addition to common risk factors for prediction of type 2 diabetes. N Engl J Med (2008) 359(21):2208-19. doi:10.1056/NEJMoa0804742

6. Meigs JB, Wilson PWF, Fox CS, Vasan RS, Nathan DM, Sullivan LM, et al. Body mass index, metabolic syndrome, and risk of type 2 diabetes or cardiovascular disease. J Clin Endocrinol Metab (2006) 91(8):2906-12. doi:10.1210/ jc.2006-0594 pathway as that of the disease itself may not improve the predictability of the disease.

\section{OUTSTANDING QUESTIONS}

How do these identified signature molecules like miRNA apply as biomarkers in the context of larger population with genetic variations? Owing to their association with multiple targets, the specificity of miRNA is an issue. Will profiling of miRNAs in body fluids and proteins at different pathophysiological stages of disease using larger study groups help in the selection of potential candidates among identified biomarkers? Further research is needed to understand the mechanism of regulation of these biomolecules and how their altered levels in body fluids specifically relate to $\mathrm{T} 2 \mathrm{DM}$.

\section{AUTHOR CONTRIBUTIONS}

The primary manuscript was prepared by SV and RS with idea input from VS.

\section{ACKNOWLEDGMENTS}

VS lab is funded by grants from NCCS (intramural) and DBT (BT/PR14109/BRB/10/812/2010). SV is supported by SERBNPDF fellowship from DST, Govt. of India. RS is supported by fellowship from the Department of Biotechnology, India.

\section{FUNDING}

The fund for this work is from the Department of Biotechnology, Ministry of Science and Technology (BT/PR14109/ $\mathrm{BRB} / 10 / 812 / 2010)$ and intramural funds of the National Centre for Cell Science.

7. Chen X, Ba Y, Ma L, Cai X, Yin Y, Wang K, et al. Characterization of microRNAs in serum: a novel class of biomarkers for diagnosis of cancer and other diseases. Cell Res (2008) 18(10):997-1006. doi:10.1038/cr.2008.282

8. Graves PR, Haystead TAJ. Molecular biologist's guide to proteomics. Microbiol Mol Biol Rev (2002) 66(1):39-63. doi:10.1128/MMBR.66.1.39-63.2002

9. Lindsay RS, Funahashi T, Hanson RL, Matsuzawa Y, Tanaka S, Tataranni PA, et al. Adiponectin and development of type 2 diabetes in the Pima Indian population. Lancet (2002) 360(9326):57-8. doi:10.1016/S0140-6736(02)09335-2

10. Schmidt MI, Duncan BB, Sharrett AR, Lindberg G, Savage PJ, Offenbacher S, et al. Markers of inflammation and prediction of diabetes mellitus in adults (atherosclerosis risk in communities study): a cohort study. Lancet (1999) 353(9165):1649-52. doi:10.1016/S0140-6736(99)01046-6

11. Meigs JB, Hu FB, Rifai N, Manson JE. Biomarkers of endothelial dysfunction and risk of type 2 diabetes mellitus. JAMA (2004) 291(16):1978-86. doi:10.1001/jama.291.16.1978

12. Jiang R, Manson JE, Meigs JB, Ma J, Rifai N, Hu FB. Body iron stores in relation to risk of type 2 diabetes in apparently healthy women. JAMA (2004) 291(6):711-7. doi:10.1001/jama.291.6.711

13. Nauck MA, Baller B, Meier JJ. Gastric inhibitory polypeptide and glucagon-like peptide-1 in the pathogenesis of type 2 diabetes. Diabetes (2004) 53(Suppl 3):S190-6. doi:10.2337/diabetes.53.suppl_3.S190

14. Prokopenko I, Langenberg C, Florez JC, Saxena R, Soranzo N, Thorleifsson G, et al. Variants in MTNR1B influence fasting glucose levels. Nat Genet (2009) 41(1):77-81. doi:10.1038/ng.290

15. Bouatia-Naji N, Bonnefond A, Cavalcanti-Proença C, Sparsø T, Holmkvist J, Marchand M, et al. A variant near MTNR1B is associated with increased 
fasting plasma glucose levels and type 2 diabetes risk. Nat Genet (2009) 41(1):89-94. doi:10.1038/ng.277

16. Warren B, Pankow JS, Matsushita K, Punjabi NM, Daya NR, Grams M, et al. Comparative prognostic performance of definitions of prediabetes: a prospective cohort analysis of the Atherosclerosis Risk in Communities (ARIC) study. Lancet Diabetes Endocrinol (2017) 5(1):34-42. doi:10.1016/ S2213-8587(16)30321-7

17. Kengne AP, Beulens JWJ, Peelen LM, Moons KGM, van der Schouw YT, Schulze MB, et al. Non-invasive risk scores for prediction of type 2 diabetes (EPIC-InterAct): a validation of existing models. Lancet Diabetes Endocrinol (2014) 2(1):19-29. doi:10.1016/S2213-8587(13)70103-7

18. Guay C, Regazzi R. Circulating microRNAs as novel biomarkers for diabetes mellitus. Nat Rev Endocrinol (2013) 9:513-21. doi:10.1038/nrendo. 2013.86

19. Ebert MS, Sharp PA. Roles for microRNAs in conferring robustness to biological processes. Cell (2012) 149:505-24. doi:10.1016/j.cell.2012.04.005

20. Friedman RC, Farh KKH, Burge CB, Bartel DP. Most mammalian mRNAs are conserved targets of microRNAs. Genome Res (2009) 19(1):92-105. doi:10.1101/gr.082701.108

21. Rome S. Are extracellular microRNAs involved in type 2 diabetes and related pathologies? Clin Biochem (2013) 46:937-45. doi:10.1016/j.clinbiochem. 2013.02.018

22. Sebastiani G, Mancarella F, Ventriglia G, Nigi L, Valentini M, Grieco E, et al. MicroRNA miR-124a, a negative regulator of insulin secretion, is hyperexpressed in human pancreatic islets of type 2 diabetic patients. RNA Dis (2015) 2:1-5. doi:10.14800/rd.593

23. Wang C, Wan S, Yang T, Niu D, Zhang A, Yang C, et al. Increased serum microRNAs are closely associated with the presence of microvascular complications in type 2 diabetes mellitus. Sci Rep (2016) 6:20032. doi:10.1038/ srep20032

24. Wang XH, Qian RZ, Zhang W, Chen SF, Jin HM, Hu RM. MicroRNA-320 expression in myocardial microvascular endothelial cells and its relationship with insulin-like growth factor-1 in type 2 diabetic rats. Clin Exp Pharmacol Physiol (2009) 36(2):181-8. doi:10.1111/j.1440-1681.2008.05057.x

25. Caporali A, Meloni M, Völlenkle C, Bonci D, Sala-Newby GB, Addis R, et al. Deregulation of microRNA-503 contributes to diabetes mellitusinduced impairment of endothelial function and reparative angiogenesis after limb ischemia. Circulation (2011) 123(3):282-91. doi:10.1161/ CIRCULATIONAHA.110.952325

26. Feng B, Chakrabarti S. miR-320 regulates glucose-induced gene expression in diabetes. ISRN Endocrinol (2012) 2012:549875. doi:10.5402/2012/549875

27. Mocharla P, Briand S, Giannotti G, Dörries C, Jakob P, Paneni F, et al. AngiomiR-126 expression and secretion from circulating CD34+ and CD14+ PBMCs: role for proangiogenic effects and alterations in type 2 diabetics. Blood (2013) 121(1):226-36. doi:10.1182/blood-2012-01-407106

28. Wang SS, Li YQ, Liang YZ, Dong J, He Y, Zhang L, et al. Expression of miR$18 \mathrm{a}$ and miR-34c in circulating monocytes associated with vulnerability to type 2 diabetes mellitus and insulin resistance. J Cell Mol Med (2017) 21(12): 3372-80. doi:10.1111/jcmm.13240

29. Nathan G, Kredo-Russo S, Geiger T, Lenz A, Kaspi H, Hornstein E, et al. MiR-375 promotes redifferentiation of adult human $\beta$ cells expanded in vitro. PLoS One (2015) 10(4):e0122108. doi:10.1371/journal.pone.0122108

30. Poy MN, Eliasson L, Krutzfeldt J, Kuwajima S, Ma X, MacDonald PE, et al. A pancreatic islet-specific microRNA regulates insulin secretion. Nature (2004) 432(7014):226-30. doi:10.1038/nature03076

31. Xia HQ, Pan Y, Peng J, Lu GX. Over-expression of miR375 reduces glucoseinduced insulin secretion in Nit-1 cells. Mol Biol Rep (2011) 38(5):3061-5. doi:10.1007/s11033-010-9973-9

32. Zhu $\mathrm{H}$, Leung SW. Identification of microRNA biomarkers in type 2 diabetes: a meta-analysis of controlled profiling studies. Diabetologia (2015) 58(5):900-11. doi:10.1007/s00125-015-3510-2

33. Barutta F, Bruno G, Matullo G, Chaturvedi N, Grimaldi S, Schalkwijk C, et al. MicroRNA-126 and micro-/macrovascular complications of type 1 diabetes in the EURODIAB Prospective Complications Study. Acta Diabetol (2017) 54(2):133-9. doi:10.1007/s00592-016-0915-4

34. Zampetaki A, Kiechl S, Drozdov I, Willeit P, Mayr U, Prokopi M, et al. Plasma microRNA profiling reveals loss of endothelial MiR-126 and other microRNAs in type 2 diabetes. Circ Res (2010) 107(6):810-7. doi:10.1161/ CIRCRESAHA.110.226357
35. Lovis P, Gattesco S, Regazzi R. Regulation of the expression of components of the machinery of exocytosis of insulin-secreting cells by microRNAs. Biol Chem (2008) 389(3):305-12. doi:10.1515/BC.2008.026

36. Panda AC, Sahu I, Kulkarni SD, Martindale JL, Abdelmohsen K, Vindu A, et al. MiR-196b-mediated translation regulation of mouse insulin2 via the 5'UTR. PLoS One (2014) 9(7):e101084. doi:10.1371/journal.pone. 0101084

37. Eliasson L, Esguerra JLS. Role of non-coding RNAs in pancreatic beta-cell development and physiology. Acta Physiol (2014) 211(2):273-84. doi:10.1111/ apha. 12285

38. Salunkhe VA, Ofori JK, Gandasi NR, Salö SA, Hansson S, Andersson ME, et al. MiR-335 overexpression impairs insulin secretion through defective priming of insulin vesicles. Physiol Rep (2017) 5(21):e13493. doi:10.14814/ phy2.13493

39. Sun X, Lin J, Zhang Y, Kang S, Belkin N, Wara AK, et al. MicroRNA-181b improves glucose homeostasis and insulin sensitivity by regulating endothelial function in white adipose tissue. Circ Res (2016) 118(5):810-21. doi:10.1161/CIRCRESAHA.115.308166

40. Silva VA, Polesskaya A, Sousa TA, Corrêa VM, André ND, Reis RI, et al. Expression and cellular localization of microRNA-29b and RAX, an activator of the RNA-dependent protein kinase (PKR), in the retina of streptozotocin-induced diabetic rats. Mol Vis (2011) 17:2228-40.

41. Xie Y, Jia Y, Cuihua X, Hu F, Xue M, Xue Y. Urinary exosomal microRNA profiling in incipient type 2 diabetic kidney disease. J Diabetes Res (2017) 2017:6978984. doi:10.1155/2017/6978984

42. Njock MS, Fish JE. Endothelial miRNAs as cellular messengers in cardiometabolic diseases. Trends Endocrinol Metab (2017) 28:237-46. doi:10.1016/j. tem.2016.11.009

43. Banerjee J, Nema V, Dhas Y, Mishra N. Role of microRNAs in type 2 diabetes and associated vascular complications. Biochimie (2017) 139:9-19. doi:10.1016/j.biochi.2017.05.007

44. Higuchi C, Nakatsuka A, Eguchi J, Teshigawara S, Kanzaki M, Katayama A, et al. Identification of circulating miR-101, miR-375 and miR-802 as biomarkers for type 2 diabetes. Metabolism (2015) 64(4):489-97. doi:10.1016/j. metabol.2014.12.003

45. Luo M, Li R, Deng X, Ren M, Chen N, Zeng M, et al. Platelet-derived miR$103 \mathrm{~b}$ as a novel biomarker for the early diagnosis of type 2 diabetes. Acta Diabetol (2015) 52(5):943-9. doi:10.1007/s00592-015-0733-0

46. Marques-Rocha JL, Samblas M, Milagro FI, Bressan J, Martínez JA, Marti A. Noncoding RNAs, cytokines, and inflammation-related diseases. FASEB J (2015) 29(9):3595-611. doi:10.1096/f.14-260323

47. Ashoori MR, Rahmati-Yamchi M, Ostadrahimi A, Fekri Aval S, Zarghami N. MicroRNAs and adipocytokines: promising biomarkers for pharmacological targets in diabetes mellitus and its complications. Biomed Pharmacother (2017) 93:1326-36. doi:10.1016/j.biopha.2017.07.059

48. Bork-Jensen J, Thuesen ACB, Bang-Bertelsen CH, Grunnet LG, Pociot F, Beck-Nielsen H, et al. Genetic versus non-genetic regulation of miR-103, miR-143 and miR-483-3p expression in adipose tissue and their metabolic implications-a twin study. Genes (Basel) (2014) 5(3):508-17. doi:10.3390/ genes5030508

49. Feng B, Chen S, McArthur K, Wu Y, Sen S, Ding Q, et al. miR-146a-mediated extracellular matrix protein production in chronic diabetes complications. Diabetes (2011) 60(11):2975-84. doi:10.2337/db11-0478

50. McArthur K, Feng B, Wu Y, Chen S, Chakrabarti S. MicroRNA-200b regulates vascular endothelial growth factor-mediated alterations in diabetic retinopathy. Diabetes (2011) 60(4):1314-23. doi:10.2337/db10-1557

51. Mortuza R, Feng B, Chakrabarti S. MiR-195 regulates SIRT1-mediated changes in diabetic retinopathy. Diabetologia (2014) 57(5):1037-46. doi:10.1007/ s00125-014-3197-9

52. Wang Y, Zhao X, Wu X, Dai Y, Chen P, Xie L. MicroRNA-182 mediates sirtl-induced diabetic corneal nerve regeneration. Diabetes (2016) 65(7): 2020-31. doi:10.2337/db15-1283

53. Kato M, Zhang J, Wang M, Lanting L, Yuan H, Rossi JJ, et al. MicroRNA-192 in diabetic kidney glomeruli and its function in TGF-beta-induced collagen expression via inhibition of E-box repressors. Proc Natl Acad Sci US A (2007) 104(9):3432-7. doi:10.1073/pnas.0611192104

54. Krupa A, Jenkins R, Luo DD, Lewis A, Phillips A, Fraser D. Loss of microRNA-192 promotes fibrogenesis in diabetic nephropathy. JAm Soc Nephrol (2010) 21(3):438-47. doi:10.1681/ASN.2009050530 
55. Wang K, Zhang S, Weber J, Baxter D, Galas DJ. Export of microRNAs and microRNA-protective protein by mammalian cells. Nucleic Acids Res (2010) 38(20):7248-59. doi:10.1093/nar/gkq601

56. Zhang Z, Peng H, Chen J, Chen X, Han F, Xu X, et al. MicroRNA-21 protects from mesangial cell proliferation induced by diabetic nephropathy in db/db mice. FEBS Lett (2009) 583(12):2009-14. doi:10.1016/j.febslet. 2009.05.021

57. Dey N, Das F, Mariappan MM, Mandal CC, Ghosh-Choudhury N, Kasinath BS, et al. MicroRNA-21 orchestrates high glucose-induced signals to TOR complex 1, resulting in renal cell pathology in diabetes. J Biol Chem (2011) 286(29):25586-603. doi:10.1074/jbc.M110.208066

58. Wang Q, Wang Y, Minto AW, Wang J, Shi Q, Li X, et al. MicroRNA-377 is up-regulated and can lead to increased fibronectin production in diabetic nephropathy. FASEB J (2008) 22(12):4126-35. doi:10.1096/fj.08-112326

59. Kato M, Putta S, Wang M, Yuan H, Lanting L, Nair I, et al. TGF-beta activates Akt kinase through a microRNA-dependent amplifying circuit targeting PTEN. Nat Cell Biol (2009) 11(7):881-9. doi:10.1038/ncb1897

60. Kato M, Wang L, Putta S, Wang M, Yuan H, Sun G, et al. Post-transcriptional up-regulation of Tsc-22 by Ybx1, a target of miR-216a, mediates TGF-(beta)induced collagen expression in kidney cells. J Biol Chem (2010) 285(44): 34004-15. doi:10.1074/jbc.M110.165027

61. Long J, Wang Y, Wang W, Chang BHJ, Danesh FR. Identification of microRNA-93 as a novel regulator of vascular endothelial growth factor in hyperglycemic conditions. J Biol Chem (2010) 285(30):23457-65. doi:10.1074/ jbc.M110.136168

62. Huang Y, Liu Y, Li L, Su B, Yang L, Fan W, et al. Involvement of inflammation-related miR-155 and miR-146a in diabetic nephropathy: implications for glomerular endothelial injury. BMC Nephrol (2014) 15:142. doi:10.1186/1471-2369-15-142

63. Huang S, Zhou S, Zhang Y, Lv Z, Li S, Xie C, et al. Association of the genetic polymorphisms in pre-microRNAs with risk of ischemic stroke in a Chinese population. PLoS One (2015) 10(2):e0117007. doi:10.1371/journal. pone.0117007

64. Fu Y, Zhang Y, Wang Z, Wang L, Wei X, Zhang B, et al. Regulation of NADPH oxidase activity is associated with miRNA-25-mediated NOX4 expression in experimental diabetic nephropathy. Am J Nephrol (2010) 32(6):581-9. doi:10.1159/000322105

65. Wang B, Komers R, Carew R, Winbanks CE, Xu B, Herman-Edelstein M, et al. Suppression of microRNA- 29 expression by TGF- $\beta 1$ promotes collagen expression and renal fibrosis. J Am Soc Nephrol (2012) 23(2):252-65. doi:10.1681/ASN.2011010055

66. He F, Peng F, Xia X, Zhao C, Luo Q, Guan W, et al. MiR-135a promotes renal fibrosis in diabetic nephropathy by regulating TRPC1. Diabetologia (2014) 57(8):1726-36. doi:10.1007/s00125-014-3282-0

67. Shanmugam N, Reddy MA, Natarajan R. Distinct roles of heterogeneous nuclear ribonuclear protein $\mathrm{K}$ and microRNA-16 in cyclooxygenase-2 RNA stability induced by S100b, a ligand of the receptor for advanced glycation end products. JBiol Chem (2008) 283(52):36221-33. doi:10.1074/jbc. M806322200

68. Carè A, Catalucci D, Felicetti F, Bonci D, Addario A, Gallo P, et al. MicroRNA-133 controls cardiac hypertrophy. Nat Med (2007) 13(5):613-8. doi:10.1038/nm1582

69. Lu H, Buchan RJ, Cook SA. MicroRNA-223 regulates Glut4 expression and cardiomyocyte glucose metabolism. Cardiovasc Res (2010) 86(3):410-20. doi:10.1093/cvr/cvq010

70. Ying C, Sui-Xin L, Kang-Ling X, Wen-Liang Z, Lei D, Yuan L, et al. MicroRNA-492 reverses high glucose-induced insulin resistance in HUVEC cells through targeting resistin. Mol Cell Biochem (2014) 391(1-2):117-25. doi:10.1007/s11010-014-1993-7

71. Shen E, Diao X, Wang X, Chen R, Hu B. MicroRNAs involved in the mitogen-activated protein kinase cascades pathway during glucose-induced cardiomyocyte hypertrophy. Am J Pathol (2011) 179(2):639-50. doi:10.1016/j. ajpath.2011.04.034

72. Katare R, Caporali A, Zentilin L, Avolio E, Sala-Newby G, Oikawa A, et al. Intravenous gene therapy with PIM-1 via a cardiotropic viral vector halts the progression of diabetic cardiomyopathy through promotion of prosurvival signaling. Circ Res (2011) 108(10):1238-51. doi:10.1161/ CIRCRESAHA.110.239111
73. Reddy MA, Das S, Zhuo C, Jin W, Wang M, Lanting L, et al. Regulation of vascular smooth muscle cell dysfunction under diabetic conditions by MIR-504. Arterioscler Thromb Vasc Biol (2016) 36(5):864-73. doi:10.1161/ ATVBAHA.115.306770

74. Deng X, Liu Y, Luo M, Wu J, Ma R, Wan Q, et al. Circulating miRNA-24 and its target YKL-40 as potential biomarkers in patients with coronary heart disease and type 2 diabetes mellitus. Oncotarget (2017) 1(38):63038-46. doi:10.18632/oncotarget.18593

75. Gong Q, Lu Z, Huang Q, Ruan L, Chen J, Liang Y, et al. Altered microRNAs expression profiling in mice with diabetic neuropathic pain. Biochem Biophys Res Commun (2015) 456(2):615-20. doi:10.1016/j.bbrc.2014.12.004

76. Yousefzadeh N, Alipour MR, Ghadiri Soufi F. Deregulation of NF-кBmiR-146a negative feedback loop may be involved in the pathogenesis of diabetic neuropathy. J Physiol Biochem (2015) 71(1):51-8. doi:10.1007/ s13105-014-0378-4

77. Zhang X, Gong X, Han S, Zhang Y. MiR-29b protects dorsal root ganglia neurons from diabetic rat. Cell Biochem Biophys (2014) 70(2):1105-11. doi:10.1007/s12013-014-0029-y

78. Lee JW, Kim HJ, Kwon YS, Jun YH, Kim SK, Choi JW, et al. Serum glycated albumin as a new glycemic marker in pediatric diabetes. Ann Pediatr Endocrinol Metab (2013) 18(4):208-13. doi:10.6065/apem.2013.18.4.208

79. Kotnik P, Fischer-Posovszky P, Wabitsch M. RBP4: a controversial adipokine. Eur J Endocrinol (2011) 164:703-11. doi:10.1530/EJE-11-0431

80. Yang Q, Graham TE, Mody N, Preitner F, Peroni OD, Zabolotny JM, et al. Serum retinol binding protein 4 contributes to insulin resistance in obesity and type 2 diabetes. Nature (2005) 436(7049):356-62. doi:10.1038/ nature 03711

81. Sun L, Qi Q, Zong G, Ye X, Li H, Liu X, et al. Elevated plasma retinol-binding protein 4 is associated with increased risk of type 2 diabetes in middle-aged and elderly Chinese adults. JNutr (2014) 144(5):722-8. doi:10.3945/ jn.113.189860

82. Marques-Vidal P, Schmid R, Bochud M, Bastardot F, von Känel R, Paccaud F, et al. Adipocytokines, hepatic and inflammatory biomarkers and incidence of type 2 diabetes. The CoLaus Study. PLoS One (2012) 7(12):e51768. doi:10.1371/journal.pone.0051768

83. Lindberg S, Jensen JS, Bjerre M, Pedersen SH, Frystyk J, Flyvbjerg A, et al. Adiponectin, type 2 diabetes and cardiovascular risk. Eur J Prev Cardiol (2015) 22(3):276-83. doi:10.1177/2047487313514894

84. Nakanishi T, Koyama R, Ikeda T, Shimizu A. Catalogue of soluble proteins in the human vitreous humor: comparison between diabetic retinopathy and macular hole. J Chromatogr B Anal Technol Biomed Life Sci (2002) 776(1):89-100. doi:10.1016/S1570-0232(02)00078-8

85. Festa A, D’Agostino R, Tracy RP, Haffner SM. Elevated levels of acute-phase proteins and plasminogen activator inhibitor-1 predict the development of type 2 diabetes: the insulin resistance atherosclerosis study. Diabetes (2002) 51(4):1131-7. doi:10.2337/diabetes.51.4.1131

86. Cho WC, Yip TT, Chung WS, Leung AW, Cheng CH, Yue KK. Differential expression of proteins in kidney, eye, aorta, and serum of diabetic and non-diabetic rats. J Cell Biochem (2006) 99(1):256-68. doi:10.1002/ jcb. 20923

87. Myles DA, Rule SA, DeLucas LJ, Babu YS, Xu Y, Volanakis JE, et al. Rotation function studies of human C-reactive protein. J Mol Biol (1990) 216(3):491-6. doi:10.1016/0022-2836(90)90373-T

88. Berndt J, Klöting N, Kralisch S, Kovacs P, Fasshauer M, Schön MR, et al. Plasma visfatin concentrations and fat depot-specific mRNA expression in humans. Diabetes (2005) 54(10):2911-6. doi:10.2337/diabetes.54.10.2911

89. Considine RV, Sinha MK, Heiman ML, Kriauciunas A, Stephens TW, Nyce MR, et al. Serum immunoreactive leptin concentrations in normal-weight and obese humans. N Engl J Med (1996) 334(5):292-5. doi:10.1056/NEJM199602013340503

90. Hotta K, Funahashi T, Arita Y, Takahashi M, Matsuda M, Okamoto Y, et al. Plasma concentrations of a novel, adipose-specific protein, adiponectin, in type 2 diabetic patients. Arter Thromb Vasc Biol (2000) 20(6):1595-9. doi:10.1161/01.ATV.20.6.1595

91. Norata GD, Raselli S, Grigore L, Garlaschelli K, Dozio E, Magni P, et al. Leptin:adiponectin ratio is an independent predictor of intima media thickness of the common carotid artery. Stroke (2007) 38(10):2844-6. doi:10.1161/ STROKEAHA.107.485540 
92. Vozarova B, Weyer C, Hanson K, Tataranni PA, Bogardus C, Pratley RE. Circulating interleukin-6 in relation to adiposity, insulin action, and insulin secretion. Obes Res (2001) 9(7):414-7. doi:10.1038/oby.2001.54

93. Kolberg JA, Jorgensen T, Gerwien RW, Hamren S, McKenna MP, Moler E, et al. Development of a type 2 diabetes risk model from a panel of serum biomarkers from the Inter99 cohort. Diabetes Care (2009) 32(7):1207-12. doi:10.2337/dc08-1935

94. Christensen PK, Larsen S, Horn T, Olsen S, Parving HH. Causes of albuminuria in patients with type 2 diabetes without diabetic retinopathy. Kidney Int (2000) 58(4):1719-31. doi:10.1046/j.1523-1755.2000.00333.x

95. MacIsaac RJ, Jerums G. Diabetic kidney disease with and without albuminuria. Curr Opin Nephrol Hypertens (2011) 20:246-57. doi:10.1097/ MNH.0b013e3283456546

96. Shoukry A, Bdeer SE-A, El-Sokkary RH. Urinary monocyte chemoattractant protein-1 and vitamin D-binding protein as biomarkers for early detection of diabetic nephropathy in type 2 diabetes mellitus. Mol Cell Biochem (2015) 408(1-2):25-35. doi:10.1007/s11010-015-2479-y

97. Jiang H, Guan G, Zhang R, Liu G, Cheng J, Hou X, et al. Identification of urinary soluble E-cadherin as a novel biomarker for diabetic nephropathy. Diabetes Metab Res Rev (2009) 25(3):232-41. doi:10.1002/dmrr.940

98. Kulkarni SD, Muralidharan B, Panda AC, Bakthavachalu B, Vindu A, Seshadri V. Glucose-stimulated translation regulation of insulin by the 5 ' UTR-binding proteins. J Biol Chem (2011) 286(16):14146-56. doi:10.1074/ jbc.M110.190553

99. Grek C, Townsend DM. Protein disulfide isomerase superfamily in disease and the regulation of apoptosis. Endoplasmic Reticulum Stress Dis (2014) 1(1):4-17. doi:10.2478/ersc-2013-0001

100. Khalique A, Sarwade RD, Pandey PR, Vijayakumar MV, Bhat MK, Seshadri V. Prolonged exposure to insulin with insufficient glucose leads to impaired Glut4 translocation. Biochem Biophys Res Commun (2016) 474(1):64-70. doi:10.1016/j.bbrc.2016.04.066

101. Nicholson JK, Wilson ID. Opinion: understanding "global" systems biology: metabonomics and the continuum of metabolism. Nat Rev Drug Discov (2003) 2(8):668-76. doi:10.1038/nrd1157

102. Raamsdonk LM, Teusink B, Broadhurst D, Zhang N, Hayes A, Walsh MC, et al. A functional genomics strategy that uses metabolome data to reveal the phenotype of silent mutations. Nat Biotechnol (2001) 19(1):45-50. doi:10.1038/83496

103. Allen J, Davey HM, Broadhurst D, Heald JK, Rowland JJ, Oliver SG, et al. High-throughput classification of yeast mutants for functional genomics using metabolic footprinting. Nat Biotechnol (2003) 21(6):692-6. doi:10.1038/ nbt823

104. An J, Muoio DM, Shiota M, Fujimoto Y, Cline GW, Shulman GI, et al. Hepatic expression of malonyl-CoA decarboxylase reverses muscle, liver and whole-animal insulin resistance. Nat Med (2004) 10(3):268-74. doi:10.1038/ nm995

105. Newgard CB, An J, Bain JR, Muehlbauer MJ, Stevens RD, Lien LF, et al. A branched-chain amino acid-related metabolic signature that differentiates obese and lean humans and contributes to insulin resistance. Cell Metab (2009) 9(4):311-26. doi:10.1016/j.cmet.2009.02.002

106. Shaham O, Wei R, Wang TJ, Ricciardi C, Lewis GD, Vasan RS, et al. Metabolic profiling of the human response to a glucose challenge reveals distinct axes of insulin sensitivity. Mol Syst Biol (2008) 4:214. doi:10.1038/ msb. 2008.50

107. Zhao X, Fritsche J, Wang J, Chen J, Rittig K, Schmitt-Kopplin P, et al. Metabonomic fingerprints of fasting plasma and spot urine reveal human pre-diabetic metabolic traits. Metabolomics (2010) 6(3):362-74. doi:10.1007/ s11306-010-0203-1

108. Pietiläinen KH, Róg T, Seppänen-Laakso T, Virtue S, Gopalacharyulu P, Tang J, et al. Association of lipidome remodeling in the adipocyte membrane with acquired obesity in humans. PLoS Biol (2011) 9(6):e1000623. doi:10.1371/journal.pbio.1000623

109. Wang TJ, Larson MG, Vasan RS, Cheng S, Rhee EP, McCabe E, et al. Metabolite profiles and the risk of developing diabetes. Nat Med (2011) 17(4):448-53. doi:10.1038/nm.2307

110. Goek ON, Döring A, Gieger C, Heier M, Koenig W, Prehn C, et al. Serum metabolite concentrations and decreased GFR in the general population. Am J Kidney Dis (2012) 60(2):197-206. doi:10.1053/j.ajkd.2012. 01.014
111. Wang-Sattler R, Yu Z, Herder C, Messias AC, Floegel A, He Y, et al. Novel biomarkers for pre-diabetes identified by metabolomics. Mol Syst Biol (2012) 8:615. doi:10.1038/msb.2012.43

112. Pontiroli AE, Pizzocri P, Caumo A, Perseghin G, Luzi L. Evaluation of insulin release and insulin sensitivity through oral glucose tolerance test: differences between NGT, IFG, IGT, and type 2 diabetes mellitus. A cross-sectional and follow-up study. Acta Diabetol (2004) 41(2):70-6. doi:10.1007/s00592004-0147-x

113. Defronzo RA. From the triumvirate to the ominous octet: a new paradigm for the treatment of type 2 diabetes mellitus. Diabetes (2009) 58(4):773-95. doi:10.2337/db09-9028

114. Floegel A, Stefan N, Yu Z, Mühlenbruch K, Drogan D, Joost HG, et al. Identification of serum metabolites associated with risk of type 2 diabetes using a targeted metabolomic approach. Diabetes (2013) 62(2):639-48. doi:10.2337/db12-0495

115. Fiehn O, Timothy Garvey W, Newman JW, Lok KH, Hoppel CL, Adams SH. Plasma metabolomic profiles reflective of glucose homeostasis in nondiabetic and type 2 diabetic obese African-American women. PLoS One (2010) 5(12):e15234. doi:10.1371/journal.pone.0015234

116. Gall WE, Beebe K, Lawton KA, Adam KP, Mitchell MW, Nakhle PJ, et al. A-hydroxybutyrate is an early biomarker of insulin resistance and glucose intolerance in a nondiabetic population. PLoS One (2010) 5(5):e10883. doi:10.1371/journal.pone.0010883

117. She P,Van Horn C, Reid T, Hutson SM, Cooney RN, Lynch CJ. Obesity-related elevations in plasma leucine are associated with alterations in enzymes involved in branched-chain amino acid metabolism. AJP Endocrinol Metab (2007) 293(6):E1552-63. doi:10.1152/ajpendo.00134.2007

118. Báez-Saldaña A, Zendejas-Ruiz I, Revilla-Monsalve C, Islas-Andrade S, Cárdenas A, Rojas-Ochoa A, et al. Effects of biotin on pyruvate carboxylase, acetyl-CoA carboxylase, propionyl-CoA carboxylase, and markers for glucose and lipid homeostasis in type 2 diabetic patients and nondiabetic subjects. Am J Clin Nutr (2004) 79(2):238-43. doi:10.1093/ajcn/79.2.238

119. Suhre K, Meisinger C, Döring A, Altmaier E, Belcredi P, Gieger C, et al. Metabolic footprint of diabetes: a multiplatform metabolomics study in an epidemiological setting. PLoS One (2010) 5(11):e13953. doi:10.1371/journal. pone. 0013953

120. Wollesen F, Brattström L, Refsum H, Ueland PM, Berglund L, Berne C. Plasma total homocysteine and cysteine in relation to glomerular filtration rate in diabetes mellitus. Kidney Int (1999) 55(3):1028-35. doi:10.1046/j. 1523-1755.1999.0550031028.x

121. Rhee EP, Cheng S, Larson MG, Walford GA, Lewis GD, McCabe E, et al. Lipid profiling identifies a triacylglycerol signature of insulin resistance and improves diabetes prediction in humans. J Clin Invest (2011) 121(4):1402-11. doi:10.1172/JCI44442

122. Horie $S$, Ishii $H$, Suga $T$. Changes in peroxisomal fatty acid oxidation in the diabetic rat liver. J Biochem (1981) 90(6):1691-6. doi:10.1093/oxfordjournals.jbchem.a133645

123. Zhang $X$, Wang $Y$, Hao F, Zhou X, Han X, Tang H, et al. Human serum metabonomic analysis reveals progression axes for glucose intolerance and insulin resistance statuses. J Proteome Res (2009) 8(11):5188-95. doi:10.1021/ pr900524z

124. Doar JWH, Wynn V, Cramp DG. Blood pyruvate and plasma glucose levels during oral and intravenous glucose tolerance tests in obese and non-obese women. Metabolism (1968) 17(8):690-701. doi:10.1016/00260495(68)90053-X

125. DiGirolamo M, Newby FD, Lovejoy J. Lactate production in adipose tissue: a regulated function with extra-adipose implications. FASEB J (1992) 6(7):2405-12. doi:10.1096/fasebj.6.7.1563593

126. Ohlson LO, Larsson B, Björntorp P, Eriksson H, Svärdsudd K, Welin L, et al. Risk factors for Type 2 (non-insulin-dependent) diabetes mellitus. Thirteen and one-half years of follow-up of the participants in a study of Swedish men born in 1913. Diabetologia (1988) 31(11):798-805. doi:10.1007/BF00277480

127. Crawford SO, Hoogeveen RC, Brancati FL, Astor BC, Ballantyne CM, Schmidt MI, et al. Association of blood lactate with type 2 diabetes: the atherosclerosis risk in communities carotid MRI study. Int J Epidemiol (2010) 39(6):1647-55. doi:10.1093/ije/dyq126

128. Montonen J, Järvinen R, Knekt P, Heliövaara M, Reunanen A. Consumption of sweetened beverages and intakes of fructose and glucose predict type 2 diabetes occurrence. J Nutr (2007) 137(6):1447-54. doi:10.1093/jn/137.6.1447 
129. Kawasaki T, Akanuma H, Yamanouchi T. Increased fructose concentrations in blood and urine in patients with diabetes. Diabetes Care (2002) 25(2):353-7. doi:10.2337/diacare.25.2.353

130. Trajkovski M, Hausser J, Soutschek J, Bhat B, Akin A, Zavolan M, et al. MicroRNAs 103 and 107 regulate insulin sensitivity. Nature (2011) 474(7353):649-53. doi:10.1038/nature10112

131. Abdul-Ghani M, Abdul-Ghani T. One-hour plasma glucose concentration and the metabolic syndrome identify subjects at high risk for future type 2 diabetes. Diabetes (2008) 31(8):1650-6. doi:10.2337/dc08-0225

132. Jagannathan R, Buysschaert M, Medina JL, Katz K, Musleh S, Dorcely B, et al. The 1-h post-load plasma glucose as a novel biomarker for diagnosing dysglycemia. Acta Diabetol (2018). doi:10.1007/s00592-018-1105-3
Conflict of Interest Statement: The authors declare that the research was conducted in the absence of any commercial or financial relationships that could be construed as a potential conflict of interest.

Copyright (c) 2018 Vaishya, Sarwade and Seshadri. This is an open-access article distributed under the terms of the Creative Commons Attribution License (CC BY). The use, distribution or reproduction in other forums is permitted, provided the original author(s) and the copyright owner are credited and that the original publication in this journal is cited, in accordance with accepted academic practice. No use, distribution or reproduction is permitted which does not comply with these terms. 